\title{
FGF-Dependent, Context-Driven Role for FRS Adapters in the Early Telencephalon
}

\author{
Sayan Nandi, ${ }^{1,2}$ Grigoriy Gutin, ${ }^{1,2}$ Christopher A. Blackwood, ${ }^{1,2}$ Nachiket G. Kamatkar, ${ }^{1,2}$ Kyung W. Lee, ${ }^{3}$ \\ Gordon Fishell, ${ }^{4}$ Fen Wang, ${ }^{5}{ }^{-}$Mitchell Goldfarb, ${ }^{3}$ and ${ }^{\circ}$ Jean M. Hébert ${ }^{1,2}$ \\ ${ }^{1}$ Department of Neuroscience and ${ }^{2}$ Department of Genetics, Albert Einstein College of Medicine, Bronx, New York 10461, ${ }^{3}$ Department of Biochemistry and \\ Molecular Biology, Mount Sinai School of Medicine, New York, New York 10029, ${ }^{4}$ Smilow Neuroscience Program, Departments of Cell Biology and Neural \\ Science, New York University Langone Medical Center, New York, New York 10016, and ${ }^{5}$ Center for Cancer and Stem Cell Biology, Institute of Biosciences \\ and Technology, Texas A\&M Health Science Center, Houston, Texas 77030
}

FGF signaling, an important component of intercellular communication, is required in many tissues throughout development to promote diverse cellular processes. Whether FGF receptors (FGFRs) accomplish such varied tasks in part by activating different intracellular transducers in different contexts remains unclear. Here, we used the developing mouse telencephalon as an example to study the role of the FRS adapters FRS2 and FRS3 in mediating the functions of FGFRs. Using tissue-specific and germline mutants, we examined the requirement of Frs genes in two FGFR-dependent processes. We found that Frs 2 and Frs3 are together required for the differentiation of a subset of medial ganglionic eminence (MGE)-derived neurons, but are dispensable for the survival of early telencephalic precursor cells, in which any one of three FGFRs (FGFR1, FGFR2, or FGFR3) is sufficient for survival. Although FRS adapters are dispensable for ERK-1/2 activation, they are required for AKT activation within the subventricular zone of the developing MGE. Using an FRS2,3-binding site mutant of Fgfr 1 , we established that FRS adapters are necessary for mediating most or all FGFR1 signaling, not only in MGE differentiation, but also in cell survival, implying that other adapters mediate at least in part the signaling from FGFR2 and FGFR3. Our study provides an example of a contextual role for an intracellular transducer and contributes to our understanding of how FGF signaling plays diverse developmental roles.

Key words: FRS2; FRS3; signal transduction; signaling adapter; telencephalon

\section{Significance Statement}

FGFs promote a range of developmental processes in many developing tissues and at multiple developmental stages. The mechanisms underlying this multifunctionality remain poorly defined in vivo. Using telencephalon development as an example, we show here that FRS adapters exhibit some selectivity in their requirement for mediating FGF receptor (FGFR) signaling and activating downstream mediators that depend on the developmental process, with a requirement in neuronal differentiation but not cell survival. Differential engagement of FRS and non-FRS intracellular adapters downstream of FGFRs could therefore in principle explain how FGFs play several distinct roles in other developing tissues and developmental stages.

\section{Introduction}

A central question in biology that remains poorly addressed is how do so few families of extracellular signals such as FGFs me-

\footnotetext{
Received Sept. 19, 2016; revised April 7, 2017; accepted April 25, 2017.

Author contributions: S.N., G.G., M.G., and J.M.H. designed research; S.N., G.G., C.A.B., N.G.K., and K.W.L. performed research; K.W.L., G.F., F.W., and M.G. contributed unpublished reagents/analytic tools; S.N., G.G., N.G.K., K.W.L., M.G., and J.M.H. analyzed data; S.N. and J.M.H. wrote the paper.

This work was supported by the National Institutes of Health (Grants MH083804 and MH070596 to J.M.H. and Grant K12GM102779 to C.A.B.) and the HirschI/Weill-Caulier Foundation (J.M.H.). We thank Drs. Philippe Soriano (Mount Sinai Hospital, NY), Juha Partanen (Helsinki), and Raj Ladher (RIKEN, Kobe) for the Fgfr ${ }^{\Delta \text { FRS/+ }}$ and Fgfr ${ }^{\mathrm{Y} 776 \mathrm{~F} /+}$ mice.

The authors declare no competing financial interests.

Correspondence should be addressed to either Jean M. Hébert or Sayan Nandi, Department of Neuroscience, Albert Einstein College of Medicine, 1399 Morris Park Avenue, Bronx, NY 10461. E-mail: jean.hebert@einstein.yu.edu or sayan.nandi@einstein.yu.edu.
}

diate so many functions throughout development and in adulthood? One reason for this lack of understanding is that few studies have examined various intracellular signal transduction modules in specific contexts in vivo, relying instead on cell culture and biochemical analyses.

The FGF signaling system has undergone enormous expansion in mammals compared with invertebrates. Twenty-two FGF ligands and cell-adhesion molecules acting as ligands, can signal via four cell-surface FGF receptors (FGFRs) (Williams et al., 1994a; Mason, 2007). Tissue-specific alternative splicing of Fgfr genes confers differential ligand-binding properties (Johnson et

D0I:10.1523/JNEUROSCI.2931-16.2017

Copyright $\odot 2017$ the authors $\quad 0270-6474 / 17 / 375690-09 \$ 15.00 / 0$ 

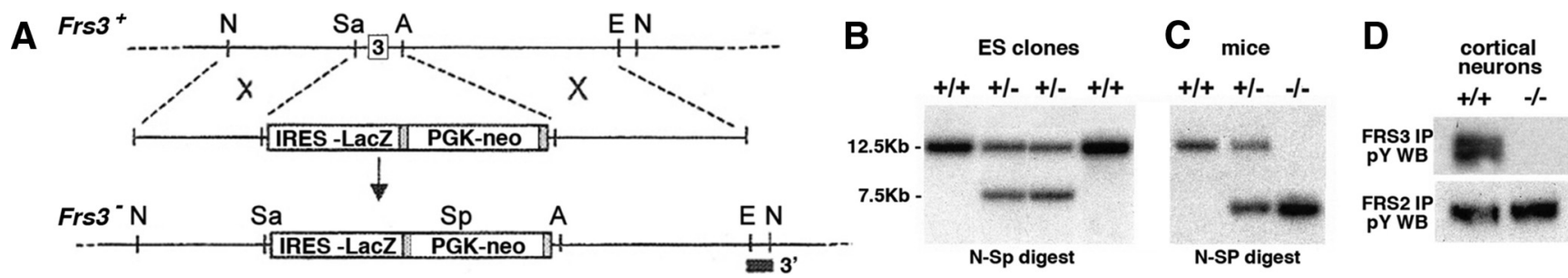

Figure 1. Construction of Frs3 knock-out mice. A, Frs ${ }^{-1-}$ mice were generated by replacing exon 3 with an Ires-LacZ/PGK-neo cassette. Restriction enzyme sites: A, Ascl; E, EcoRl; N, Nhel; Sa, Sacl; Sp, Spel. Insertion of the cassette introduces a Spel site. $\boldsymbol{B}$, C, Southern blot analysis of genomic DNA from ES cell clones $(\boldsymbol{B})$ and mice $(\boldsymbol{C})$; DNA was digested with Nhel and Spel and blots are probed with an EcoRl-Nhel fragment flanking the targeting construct (wild-type allele: $12.5 \mathrm{~Kb}$ band; mutant allele: $7.5 \mathrm{~Kb}$ band). $\boldsymbol{D}$, Phospho-FRS3 protein is undetectable in Frs3 ${ }^{-1}{ }^{-}$cortical $^{-}$ neurons stimulated with $50 \mathrm{ng} / \mathrm{ml}$ BDNF for $10 \mathrm{~min}$, lysed, and immunoprecipitated using either FRS2 or FRS3 antibodies.

al., 1991; Miki et al., 1992). This alone, however, cannot explain the pleiotropic roles played by FGFs in so many different contexts from development to physiology (Basson et al., 2008; Guillemot and Zimmer, 2011; Hébert, 2011). As an example, mutations in Fgfr1 result in diverse skeletal, hematopoietic, and nervous system diseases (Muenke et al., 1994; Xiao et al., 1998; Dode et al., 2003). Here, we address how specificity is governed in the FGF signaling pathway. Namely, can the choice of intracellular mediators by FGFRs govern functional specificity within a given context?

FGFRs can activate canonical intracellular transducers such as FRS and PLC $\gamma$ directly, as well as other transducers such as Crk/ Crkl and Grb14, thereby initiating multiple downstream signaling cascades (Williams et al., 1994b; Partanen et al., 1998; Turner and Grose, 2010; Goetz and Mohammadi, 2013; Brewer et al., 2015). The FRS family of docking proteins has two members, FRS2 (also called FRS2 $\alpha$ ) and FRS3 (also called FRS2 $\beta$ ), which constitutively interact with the juxtamembrane region of FGFRs (Xu et al., 1998; Gotoh et al., 2004; Hoch and Soriano, 2006). After receptor activation induced by ligand binding, FRS proteins can become tyrosine phosphorylated and recruit Grb2, Gab1, and SHP2, leading to the activation of the MAPK and PI3K pathways (Hadari et al., 2001; Gotoh et al., 2005; Gotoh, 2008; Goetz and Mohammadi, 2013; Brewer et al., 2015).

Previously, we used telencephalon development as a model to study FGF signaling (Gutin et al., 2006; Storm et al., 2006; Tole et al., 2006; Hébert and Fishell, 2008; Paek et al., 2009; Paek et al., 2011). Fgfr1, Fgfr2, and Fgfr3 are expressed in precursor cells throughout telencenpalon development (Hébert et al., 2003; Tole et al., 2006) and deletion in mice of all three genes at once in early telencephalic precursors resulted in ablation of the telencephalon due to precursor cell death (Paek et al., 2009; Paek et al., 2011), whereas simultaneous deletion of two receptor genes revealed specific requirements of FGFRs in patterning the ventral telencephalon at later time points during development (Gutin et al., 2006). Although all FGFRs are likely capable of signaling through FRS proteins (Gotoh et al., 2005; Eswarakumar et al., 2006; Gotoh, 2008; Goetz and Mohammadi, 2013), in this study, we address using genetic approaches in mice to determine whether the dependence of FGFR function on FRS proteins varies in different processes of telencephalon development.

\section{Materials and Methods}

Mice. The experiments described in this study were approved by the Institutional Animal Care and Use Committee of the Albert Einstein College of Medicine. Foxg1 ${ }^{\text {Cre }}$ (Hébert and McConnell, 2000), Frs $2^{\text {Flox }}$ (Zhang et al., 2008), Fgfr ${ }^{\text {Flox }}, F g f r 2^{\text {Flox }}, F g f r 3^{\text {Flox }}$ (Kang et al., 2014), Fgfrl ${ }^{\triangle \mathrm{FRS}}$ (Hoch and Soriano, 2006), and Fgfr1 ${ }^{\mathrm{Y} 776 \mathrm{~F}}$ (Partanen et al., 1998) alleles were maintained and genotyped as described previously. $\mathrm{Frs}^{-1-}$ mice were generated by replacing exon 3 with an IRES-LacZ/
PGK-neo cassette in R1 embryonic stem cells (Fig. 1A). Homologous recombination was confirmed by Southern blot using a $3^{\prime}$ external probe (Fig. $1 B, C$ ). After blastocyst injections, chimeric males were mated to Swiss Webster mice and the offspring were identified by Southern blot analysis and PCR genotyped with: P1, 5'ATTAAGGGCCAGCTCATT; P2, 5'TTCAAGTGTTCGAGGGCA; and P3, 5'CAGGACTGATCCATC CTCAG, with P1 and P3 amplifying an $\sim 350$ bp mutant product and P2 and P3 an $\sim 500$ bp wild-type product (Fig. $1 D$ and data not shown).

IHC analyses. Whole embryonic day 9.0 (E9.0) to E13.5 embryos were fixed with $4 \%$ paraformaldehyde in PBS, incubated in $10 \%$ ( $4 \mathrm{~h}$ ) and $20 \%$ (overnight) sucrose in PBS $\left(4^{\circ} \mathrm{C}\right)$, and embedded in optimal cutting temperature medium. Cryosections $(14 \mu \mathrm{m})$ were immunostained with the following antibodies: FRS3, goat polyclonal, 1:100 (Santa Cruz Biotechnology); DLX2, mouse monoclonal, 1:75 (Santa Cruz Biotechnology); NKX2.1, rabbit monoclonal, 1:300 (Abcam); PAX6, rabbit polyclonal, 1:250 (Invitrogen); LHX8, rabbit monoclonal, 1:300 (Abcam); LHX6, rabbit polyclonal, 1:200 (Abcam); p-HH3, rabbit monoclonal, 1:200 (Cell Signaling Technology); GSH2, rabbit polyclonal, 1:800 (Millipore); p-ERK-1/2, rabbit monoclonal, 1:150 (Cell Signaling Technology); and p-AKT, rabbit monoclonal, 1:100 (Cell Signaling Technology). Sections were mounted with Prolong Diamond Antifade Mounting Medium with DAPI (Invitrogen) and imaged using a Zeiss fluorescent microscope with Axiovision software.

RNA in situ hybridization. ${ }^{35} \mathrm{~S}$ in situ hybridizations were performed as described previously on fresh frozen sections $(14 \mu \mathrm{m})$ with a cresyl violet counterstain (Frantz et al., 1994).

TUNEL assay. TUNEL reactions were performed on $16 \mu \mathrm{m}$ freshfrozen sections following the manufacturer's protocol (Roche In situ Cell Death Kit).

Statistical analyses. Quantitation was with ImageJ unless otherwise mentioned and data are presented as the average \pm SEM. Significance was determined using Student's $t$ test.

\section{Results}

FRS adapters are nonessential for FGF-dependent survival of early telencephalic precursor cells

Loss of three Fgfr genes from telencephalic precursor cells leads to a complete loss of the telencephalon due to precursor cell death at E8.75 (Paek et al., 2009). We therefore investigated whether FRS adapters were required first for telencephalon development and second for mediating FGFR1 signaling. The Frs gene family consists of Frs2 and Frs3 (Gotoh, 2008). Frs2 germline knock-out mice die by E7.5 due to extraembryonic deficits (Hadari et al., 2001; Gotoh et al., 2005). To assess the role of Frs2 in the telencephalon, a conditional Frs $2^{\text {Flox }}$ allele (Lin et al., 2007) was recombined using a Foxg $1^{\text {Cre }}$ allele, which recombines floxed alleles in telencephalic precursor cells by E9.0 (Hébert and McConnell, 2000; Paek et al., 2009). Because no knock-out or conditional allele of Frs3 had been reported, we generated an Frs3 knockout allele by substituting exon 3, which encodes the essential phosphotyrosine-binding domain, with an IRES-LacZ/PGK-neo 


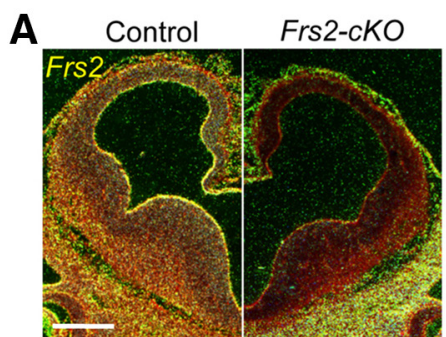

B

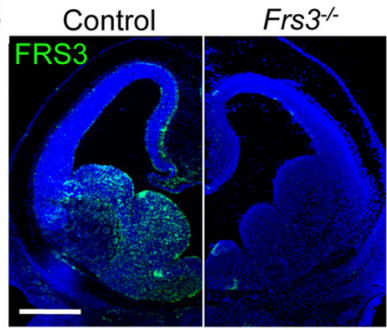

C

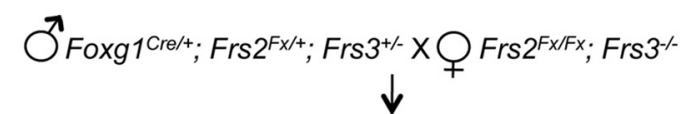

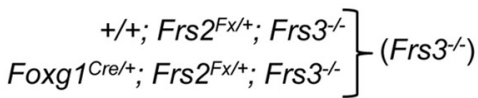

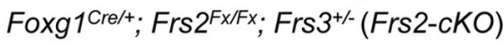

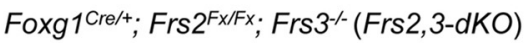
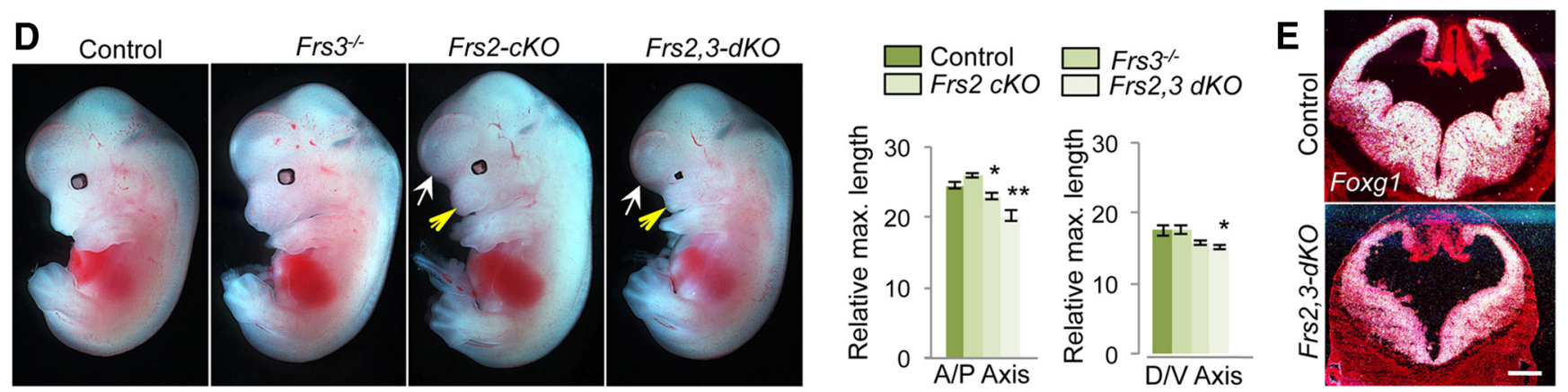

Figure 2. FRS adapters largely compensate for each other, but are dispensable for initial formation of the telencephalon. $A$, In situ hybridization revealed Frs $2 \mathrm{mRNA}$ in coronal sections of E12.5 control but not Frs2-cKO mutant telencephalons (Frs2 labeling, yellow; cresyl violet counterstain, red). B, Detection of FRS3 protein in coronal sections of E13.5 control but not Frs3 ${ }^{-1}{ }^{-}$mutant telencephalons (anti-FRS3 staining, green; DAPI counterstain, blue). FRS2 and FRS3 expression overlap in the ventral telencephalon. C, Mating scheme and mutant nomenclature. D, Compared with controls, Frs2,3-dKO and, to a lesser extent, Frs2-cKO mutants had smaller telencephalons (white arrows), eyes, and frontonasal processes (yellow arrowheads) at E13.5. Quantitation of maximal telencephalic A/P and D/V lengths normalized to whole body length and compared with controls. ${ }^{*} p<0.05$; ${ }^{* *} p<0.001 ; n \geq 5$. E, Unlike mutants in which FGFR function is abolished (Paek et al., 2009), Frs2,3-dKO mice still form a telencephalon defined by Foxg 1 mRNA (white) on E12.5 coronal sections (counterstain, red). Scale bar, $500 \mu \mathrm{m}$.
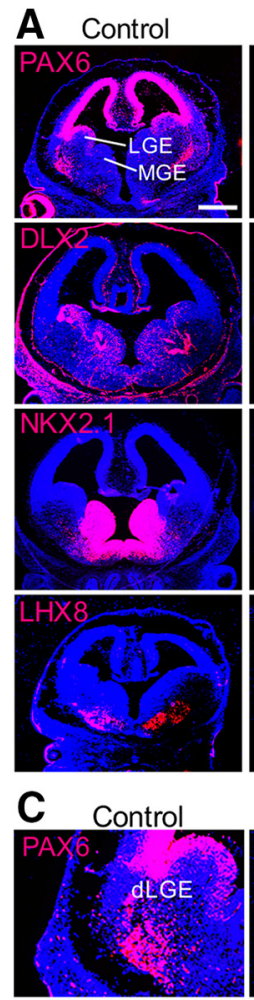

Frs $3^{-1}$

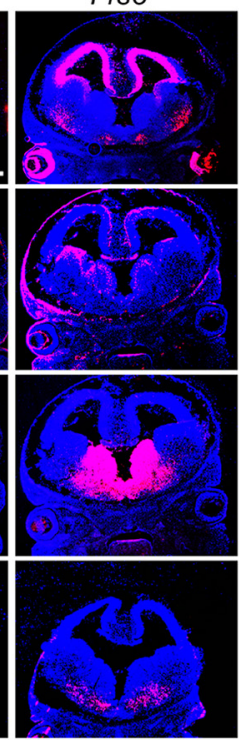

Frs2,3-dKO

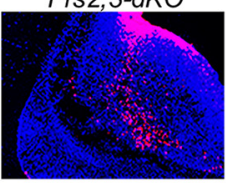

Frs2-cKO

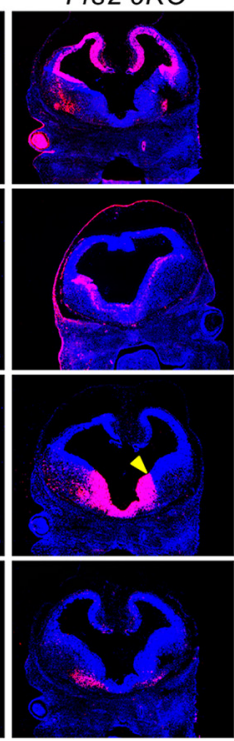

D
Frs2,3-dKO
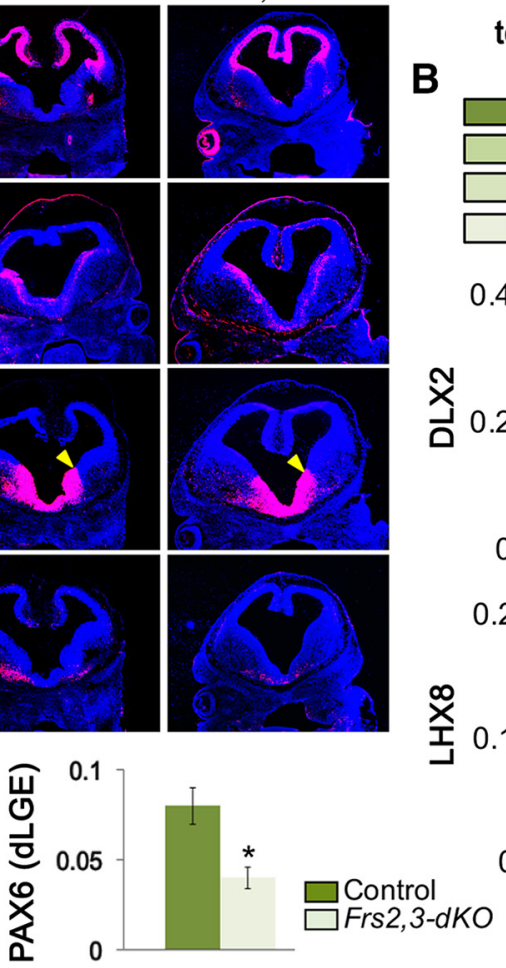

B
Labeled areas / total telencephalic area
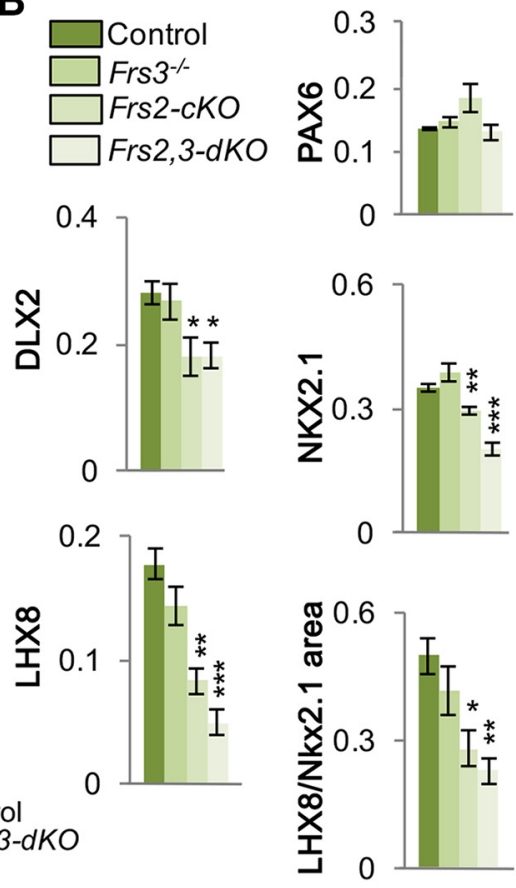

Figure 3. FRS adapters are required in ventral telencephalon development with a dominant role for FRS2. A, Immunohistochemical analysis of E13.5 coronal sections for PAX6 (dorsal), DLX2 (ventral), NKX2.1 (MGE precursors and preoptic area), and LHX8 (differentiating MGE field) revealed ventral deficits (arrowheads) in Frs2-cK0 and Frs2,3-dKO mutants. Counterstain, DAPI (blue).

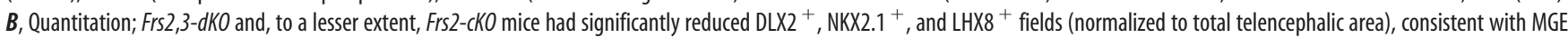
deficits. In these mutants, a reduction in the LHX8 ${ }^{+} / \mathrm{NKX} 2.1^{+}$ratio further indicated a deficit in precursor differentiation. $C$, Enlarged images from $A$ of PAX6 ${ }^{+}$areas in the dorsal LGE in control and Frs2,3-dKO mice. D, Quantitation revealed a significant reduction in the PAX6 ${ }^{+}$dLGE domain in mutants. dLGE, Dorsal LGE. ${ }^{*} p<0.05 ;{ }^{* * *} p<0.01 ;{ }^{* * *} p<0.001 ; n \geq 3$. Scale bar, 500 $\mu$ m. 


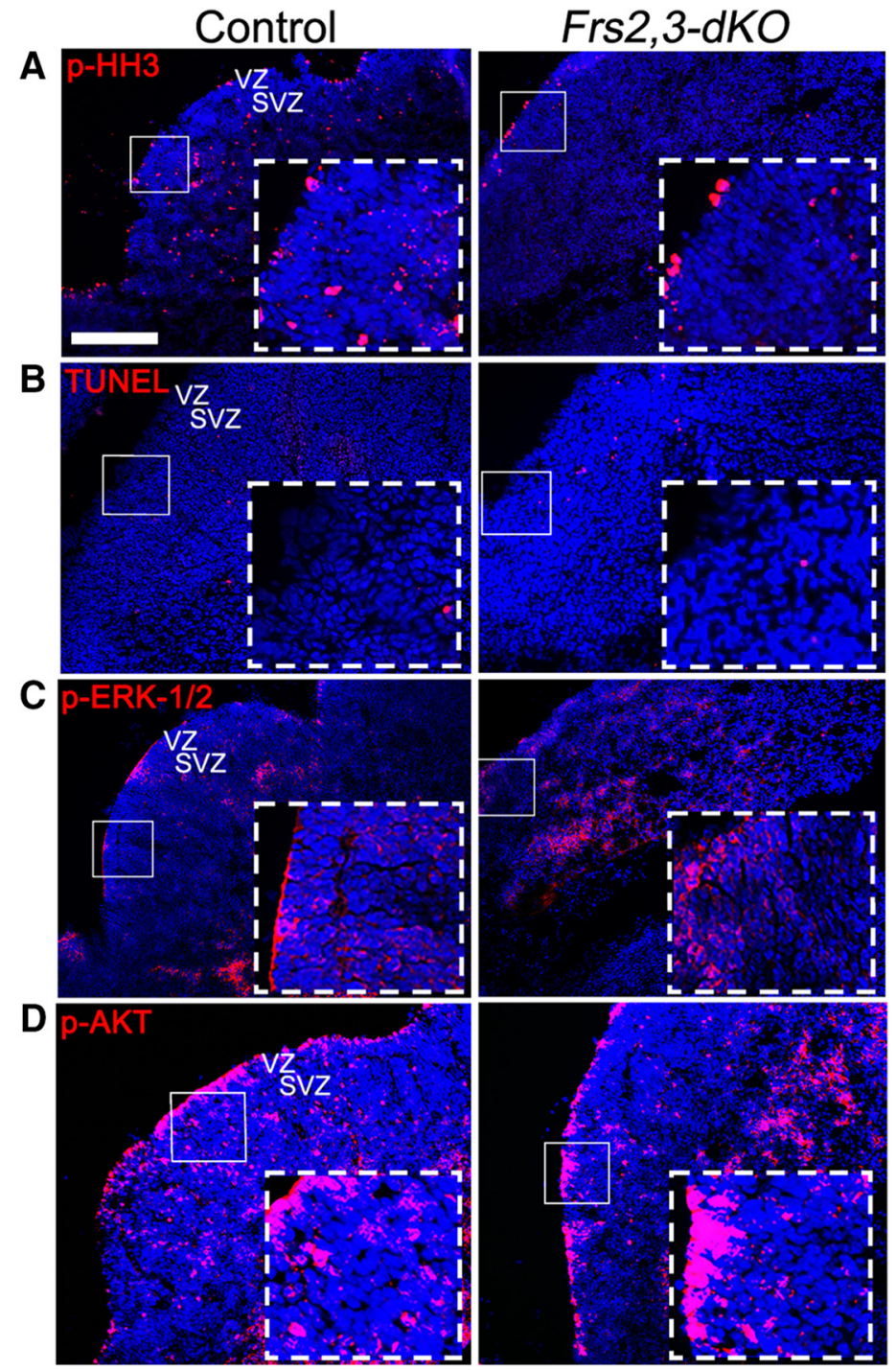

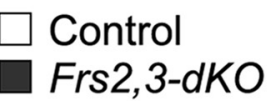
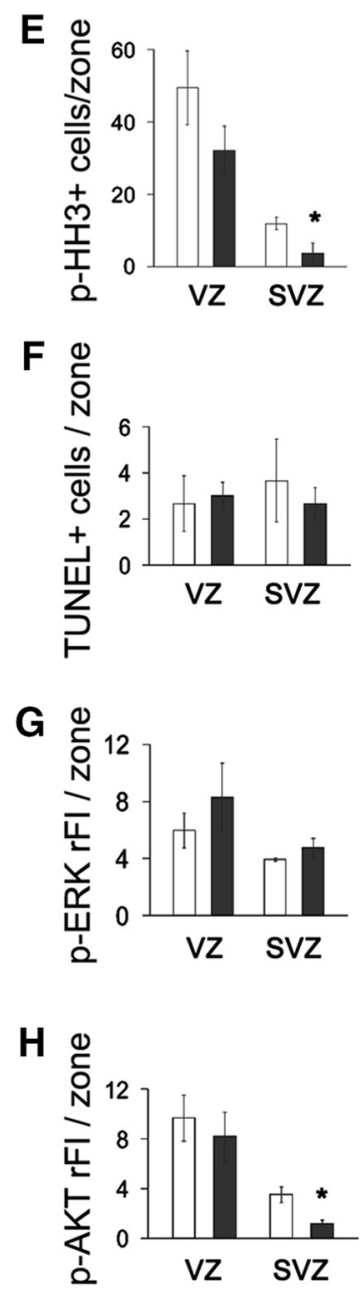

Figure 4. FRS adapters are required for AKT activation and the differentiation of neurons within the MGE. A, B, Frs2,3-dKO mice at E13.5 displayed attenuated p-HH3 ${ }^{+}$(but not TUNEL ${ }^{+}$) cell numbers in the SVZ of the MGE. C, D, Frs2,3-dKO mice at E13.5 displayed reduced p-AKT (but not p-ERK-1/2) immunofluoresence (IF) intensity in the SVZ. Counterstain, DAPI (blue). No differences in p-HH3 and p-AKT staining were observed in the mutant VZ. E13.5 VZ and SVZ areas are defined as areas up to $20 \mu \mathrm{m}$ from the ventricular surface and up to $30 \mu \mathrm{m}$ from the VZ, respectively, as defined previously by Gutin et al. (2006). Insets, Enlargement of the boxed areas. $\boldsymbol{E}-\boldsymbol{H}$, Quantitation of the number of p-HH3 ${ }^{+}(\boldsymbol{E})$ and TUNEL ${ }^{+}(\boldsymbol{F})$ cells and of p-ERK-1/2 (G) and p-AKT $(\boldsymbol{H})$ relative fluoresence intensity $(\mathrm{rFI})$ over their respective NKX2. ${ }^{+}$VZ or SVZ fields. ${ }^{*} p<0.05 . n \geq 3$. Scale bar, $250 \mu \mathrm{m}$.
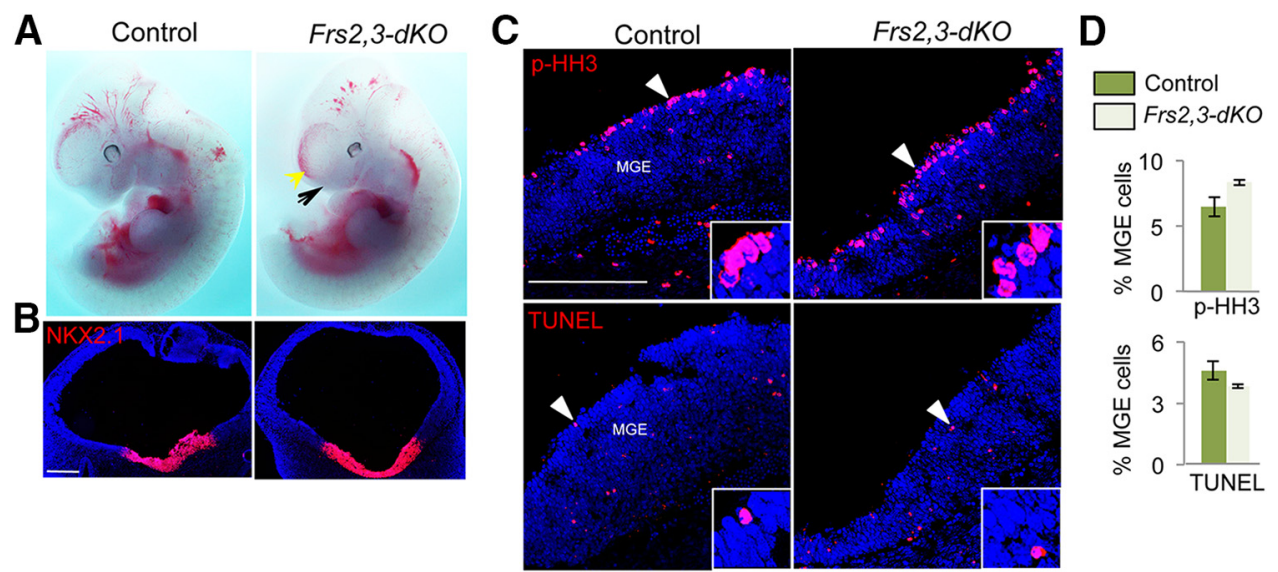

Figure 5. Normal MGE induction in Frs2,3-dKO mice. A, Frs2,3-dKO mutants at E10.5 had a slightly smaller telencephalon (yellow arrow), eyes, and frontonasal process (black arrow). B, MGE precursor fields, identified by immunostaining with NKX2.1 at E10.5, were similar in controls and mutants. Counterstain, DAPI (blue). Scale bar, $500 \mu \mathrm{m}$. C, Frs2,3-dKO mice at E10.5 exhibited normal levels of p-HH3 (mitotic marker) and TUNEL (apoptotic marker) staining in MGE precursors. Insets, Enlargements of areas indicated by arrowheads. Counterstain, DAPI (blue). Adjacent sections were stained with NKX2.1 (data not shown). $\boldsymbol{D}$, Ouantitation of the number of $\mathrm{p}-\mathrm{HH} 3^{+}$and TUNEL ${ }^{+}$cells over their respective NKX2.1 ${ }^{+}$fields. Cells were counted from the ventricular surface to the pia. $n=2$. 


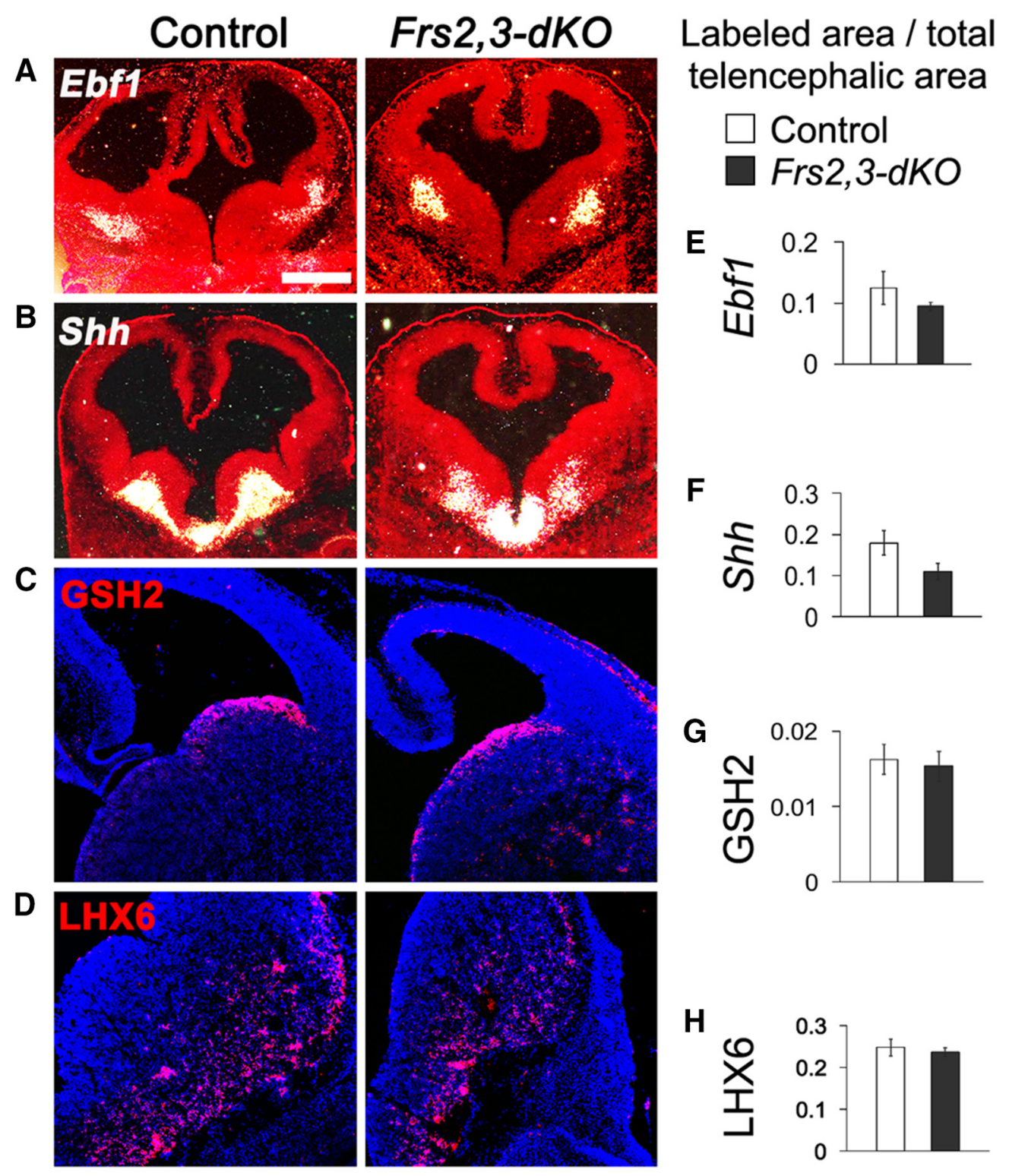

Figure 6. LGE and the differentiating field of cortical GABAergic interneurons in the MGE are grossly normal in Frs2,3-dKO mice. A, B, RNA in situ hybridization for Ebf1 (a marker of differentiating LGE neurons, white) and Shh (a marker primarily of differentiating GABAergic MGE neurons, white) at E12.5. C, D, Immunohistochemical analysis for GSH2 (a marker for LGE progenitors) and LHX6 (a marker of differentiating GABAergic precursors in the MGE, red) at E13.5 (counterstain, DAPI, blue). $\boldsymbol{E}-\boldsymbol{H}$, Quantitation revealed no significant differences in the domains of expression between controls and Frs2,3-dKO embryos. $n=2$. Scale bars: $A, B, 500 \mu \mathrm{m} ; \boldsymbol{C}, \boldsymbol{D}, 250 \mu \mathrm{m}$.

cassette (Fig. 1A-D). Adult Frs $3^{-1-}$ mice appeared normal and were fertile.

Frs2 mRNA was broadly detected in tissues including the telencephalon from E9.0 to E13.5 (Fig. $2 A$ and data not shown; Gotoh et al., 2004), whereas FRS3 protein was restricted to ventral areas (Fig. 2B), consistent with its mRNA pattern (Gotoh et al., 2004). Despite mixed reports of compensatory and distinct functions for Frs2 and Frs3 (Gotoh et al., 2004; Huang et al., 2006; Minegishi et al., 2009; Hryciw et al., 2010), the overlap in their ventral telencephalic expression suggested a potential compensatory role for FRS2 and FRS3 in this region. Therefore, we examined several Frs 2 and Frs 3 compound mutant genotypes (Fig. $2 C$ ). Mutant embryos of all genotypes were obtained at the ages indicated in the expected Mendelian ratios with no signs of necrosis. Controls were littermates that did not carry Cre and/or were heterozygous for Frs2, Frs3, or both and, in none of these cases could a phenotype be detected. Whole E13.5 Frs $3^{-1-}$ and
Frs2-cKO embryos appeared grossly normal (Fig. 2D). Although $\mathrm{Frs}^{-1-}$ mice with either one or two functional copies of Frs2 had a normal telencephalon at E13.5, Frs2-cKO mice had slightly smaller telencephalons along the $\mathrm{A} / \mathrm{P}$ axis (by $\sim 13 \%$ ) and slightly smaller eyes and frontonasal prominences (Fig. 2D). Consistent with compensatory roles for Frs 2 and Frs3, Frs2,3-dKO mice, compared with either Frs2-cKO or Frs $3^{-1-}$ mutants, showed a more severe reduction in telencephalic size along the $\mathrm{A} / \mathrm{P}(\sim 24 \%)$ and $\mathrm{D} / \mathrm{V}$ axes $(\sim 16 \%)$, along with smaller eyes and frontonasal prominences (Fig. $2 D$ ). These results suggest that the in vivo roles of FRS proteins are compensatory in nature.

Interestingly, in contrast to $\mathrm{Fg} f \mathrm{r}$ triple-null mice, $\mathrm{Frs} 2,3-\mathrm{dKO}$ mice formed a telencephalon (Fig. 2E), suggesting that FRS proteins are not individually or combinatorially required for the early FGF-dependent survival of telencephalic precursor cells and that other FGFR adapters play roles in this process. Therefore, 

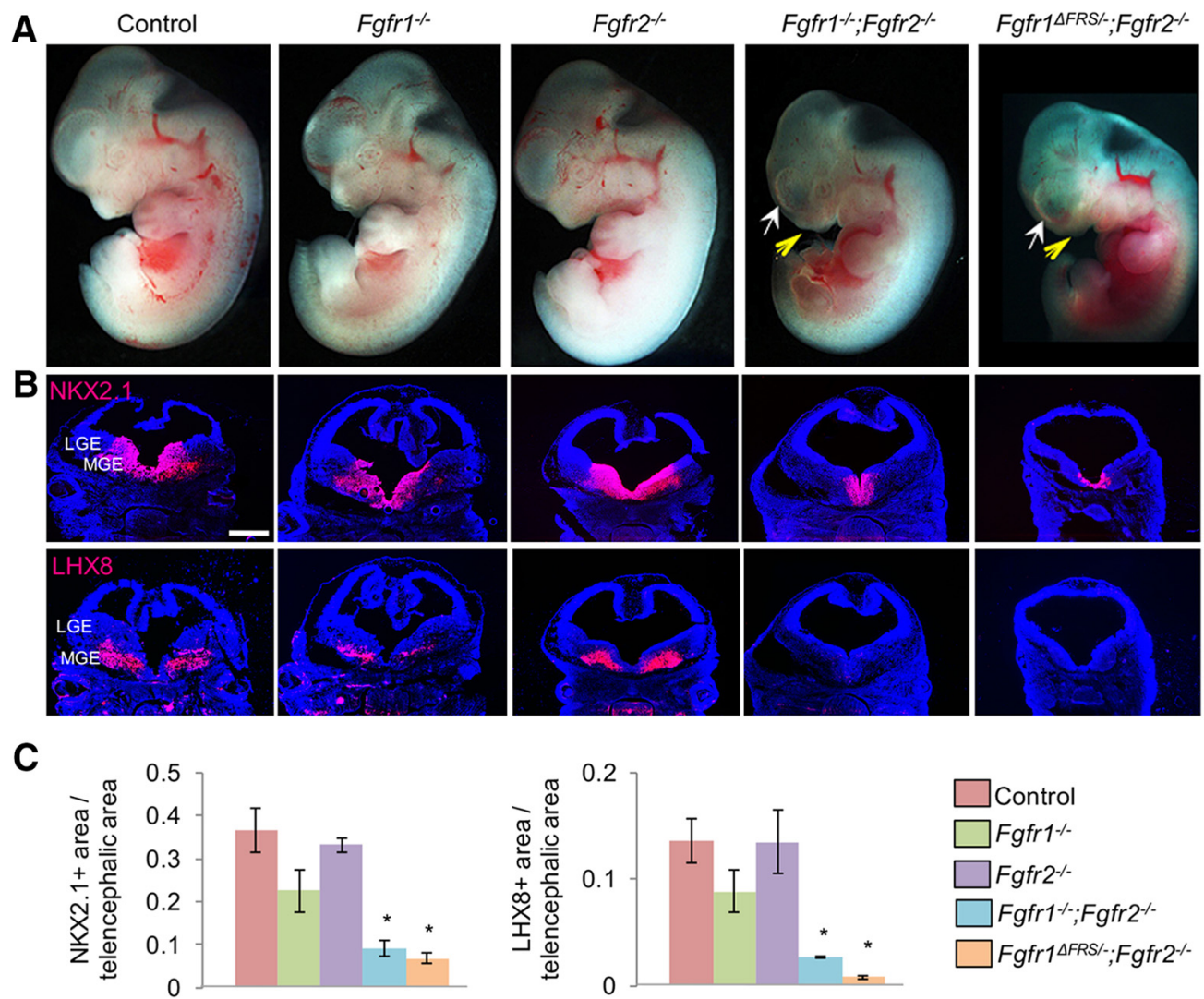

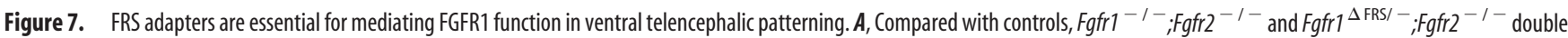
mutants had smaller telencephalons (white arrows), eyes, and frontonasal processes (yellow arrowheads) at E12.5. Note that the size of the telencephalon in these double mutants was smaller than in the Frs2,3-dKO mutants (Fig. 2D). B, Immunohistochemical analysis for NKX2.1 and LHX8 of E13.5 coronal telencephalic sections from Foxg $1^{\text {Cre }}$-driven single (Fgfr ${ }^{-1-}$ and Fgfr2 ${ }^{-1-}$ ) and double $\left(F g f r 1^{-1-} ; F_{f f r 2}{ }^{-1-}\right.$ and Fgfr $\left.{ }^{\triangle \mathrm{FRS} /}{ }^{-} ; \mathrm{Fgfr2}{ }^{-1-}\right)$ mutants revealed that both FGFR1 and FGFR2 are required for MGE development and most or all signaling from FGFR1 requires an FRS-binding site. A more severe deficit in Frs2; Frs3 mutants (Fig. 2) compared with either Fgfr1 or Fgfr2 single mutants further suggested that both receptors use FRS adapters. C, Immunohistochemical quantitation. Comparisons were made with controls $\left(F g f r 1^{+/-} ; F g f r 2^{+/-}\right) .{ }^{*} p<0.01 ; n \geq 3$. Scale bar, $500 \mu \mathrm{m}$.

FRS proteins are not required for all FGF-dependent processes within the context of telencephalon development.

\section{FRS2 and FRS3 are together required for phosphorylation of} AKT and differentiation of a subset of neurons

General dorsoventral telencephalic patterning in Frs2 and Frs3 mutants was assessed with PAX6 (dorsal marker) and DLX2 (ventral marker). Although all mutants had normal dorsoventral boundaries marked by PAX6 and DLX2 immunoreactivity and normal sized $\mathrm{PAX}_{6}{ }^{+}$domains, the ventral $\mathrm{DLX} 2{ }^{+} \mathrm{VZ}$ was reduced in both Frs2-cKO and Frs2,3-dKO mice at E13.5 (Fig. $3 A, B)$. Furthermore, Frs2-cKO and Frs2,3-dKO mice exhibited a reduction of the NKX2.1-labeled medial ganglionic eminence (MGE) and preoptic area and LHX8-labeled differentiating domain compared with control or Frs3 ${ }^{-1-}$ mice, even when these also lacked one copy of Frs2 (Fig. $3 A, B$ ). A greater reduction of the $\mathrm{LHX}^{+}{ }^{+}$area relative to the NKX2.1 ${ }^{+}$area in both mutants suggests that FRS2 and FRS3 are together required for MGE differentiation, with FRS2 playing a dominant role.

Consistent with a role for FRS proteins in MGE differentiation, precursor cell division assessed by p-HH3 immunoreactivity within the SVZ, but not within the VZ, of the MGE was reduced in E13.5 Frs2,3-dKO mice (Fig. 4A,E). Precursor cell division at E10.5 before the onset of neurogenesis was unaffected (Fig. 5C,D), consistent with an initially normal NKX2.1 ${ }^{+}$field (Fig. $5 A, B$ ). Cell survival in the MGE measured by TUNEL stain- ing was not detectably affected in Frs2,3-dKO mutants at either stage (Figs. $4 B, F, 5 C, D$ ). Collectively, these results are consistent with FRS2 and FRS3 playing an important role in differentiation of NKX2.1 ${ }^{+}$precursor cells.

Because precursor cells in the ventral telencephalon give rise to several neuron populations, we investigated the contribution of FRS proteins in this process by examining subpopulations of neuron precursors in E13.5 control and mutant mice. Our results revealed that the domains of Shh and LHX6 expression, which mark predominantly the differentiating field of cortical GABAergic interneurons (Liodis et al., 2007; Xu et al., 2010), were comparable between control and mutant mice (Fig. $6 B, D, F, H$ ). This is in contrast to what we observed with reduced cells expressing LHX8 (Fig. 3), a marker of basal forebrain cholinergic neuron precursors induced by FGF8 (Zhao et al., 2003; Hoch et al., 2015). The lateral ganglionic eminence (LGE), although morphologically flatter, had approximately normal sized differentiating and progenitor fields marked by Ebf1 and GSH2 expression, respectively (Fig. 6A, C,E, G) (Corbin et al., 2000). However, PAX6 ${ }^{+}$ cells in the dorsal LGE, which mark a subset of dopaminergic olfactory interneuron progenitors (Kohwi et al., 2005), were significantly reduced in Frs2,3-dKO mice when compared with control mice (Fig. 3C,D). Therefore, FRS adapters selectively regulate the differentiation of a subset of ventral telencephalic neurons. Their roles in the developing telencephalon are consistent with previously 

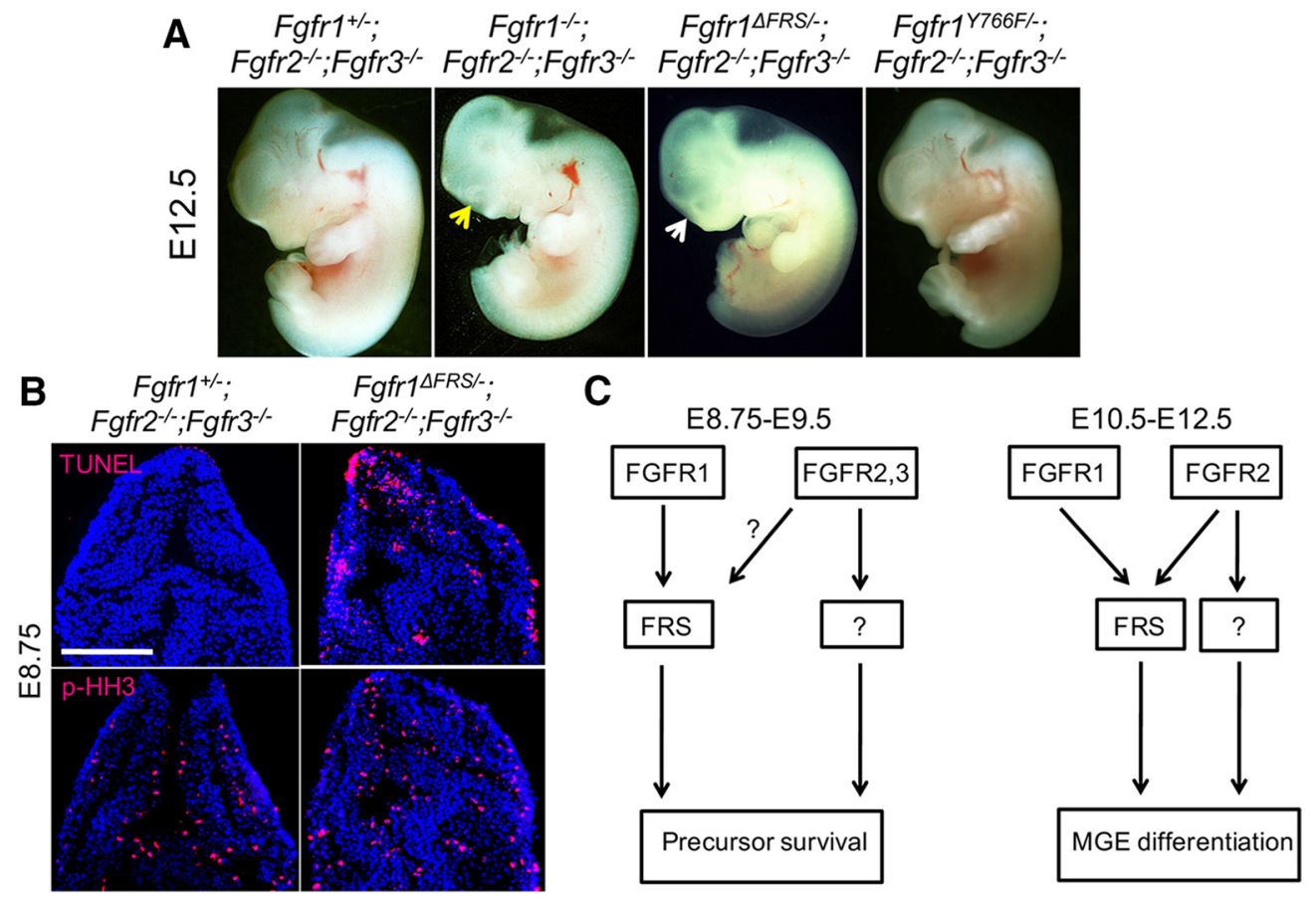

Figure 8. FRS adapters, but not PLC $\gamma$, are essential for FGFR1 function in precursor cell survival. A, Although mutants with loss of all three Fgfr genes (yellow arrow; Paek et al., 2009) or with one $\mathrm{Fgfr}^{\Delta \mathrm{FRS}}$ allele in the absence of $\mathrm{Fgfr} 2$ and $\mathrm{Fgfr}$ (white arrow) lacked a telencephalon, mutants with either one wild-type allele of $F g f r 1$ (left) or one $F g f r 1$ allele harboring a point mutation in the PLC $\gamma$-binding site (Y776F) (right) in the absence of Fgfr2 and Fgfr3 maintained grossly normal telencephalon development at E12.5, suggesting that FGFR1 signaling through FRS (but not through $\mathrm{PLC}(\gamma)$ is required. B, One wild-type allele of $F g f r 1$ in the absence of $F g f r 2$ and $F g f r 3$ maintained precursor cell survival (left) at E8.75, whereas replacing this one wild-type allele of $F g f r 1$ with the Fgfr ${ }^{\triangle \text { FRS }}$ allele failed to maintain precursor cell survival, leading to $25 \%$ TUNEL $^{+}$cells at E8.75 without affecting cell division ( $\mathrm{p}-\mathrm{HH} 3^{+}$cells), a phenotype as severe as Fgfr $1^{-1-}$; $F$ gfr $2^{-1-}$; Fgfr $^{-1-}$ mutants (A) (Paek et al., 2009). Counterstain, Hoechst (blue). Scale bar, $500 \mu \mathrm{m}$. C, FRS adapters play a nonessential role during early telencephalic precursor cell survival despite mediating most or all of FGFR1 activity, suggesting that FGFR2 and FGFR3 signal via other adapters to maintain this process. For ventral patterning, Frs2,3-dKO mice exhibited deficits that were

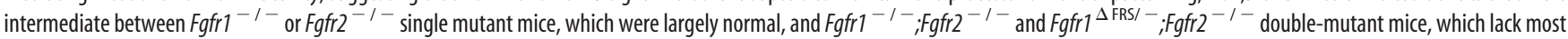
ventral cells, indicating an essential but partial role for FRS-mediated FGF signaling in this process.

described roles for FGFRs (Hébert et al., 2003; Gutin et al., 2006; Hébert and Fishell, 2008).

To identify downstream targets of FRS proteins in the developing MGE, we stained control and double mutant sections with anti-p-ERK-1/2 and p-AKT antibodies (Fig. 4C,D). Although p-ERK-1/2 levels were comparable between control and mutant mice, $\mathrm{p}$-AKT levels were reduced in SVZ, but not VZ, of mutant MGEs compared with control SVZ and VZ (Fig. 4G,H). These results show that FRS adapters are critical for AKT/PI3K activation, but are dispensable for the activation of ERK-1/2/MAPK pathway within MGE progenitors. Collectively, our results suggest that FRS adapters, via activation of the AKT/PI3K pathway, play a role in differentiation of a subset of MGE-derived neurons.

\section{FRS adapters are required to transmit most or all FGFR1 activity}

The Frs2-cKO and Frs2,3-dKO phenotypes are consistent with a role for FRS adapters in transmitting FGFR activity in the MGE. Although Foxgl ${ }^{\mathrm{Cre}}$-driven $F g f r 1$ and $F g f r 2$ single mutants appeared largely normal (Fig. $7 A, B$ ) and $F g f r 3$ was previously suggested not to contribute significantly to MGE development (Gutin et al., 2006), Foxg1 ${ }^{\text {Cre }}$-driven Fgfr1;Fgfr2 double mutants exhibit a smaller telencephalon and a severe ventral telencephalon deficit (Fig. 7 A, B; Gutin et al., 2006). Notably, the Fgfr1;Fgfr2 double-mutant phenotype has a more severe loss of ventral tissue than the Frs2,3-dKO phenotype, suggesting that FRS transduces some but not all FGFR signaling.

Because a single wild-type allele of Fgfrl in Foxg1 ${ }^{\mathrm{Cre}}$-driven mutant $F g f r 2$ and $F g f r 2 ; F g f r 3$-deficient backgrounds $\left(F g f r 1^{+/-}\right.$;
$\mathrm{Fgfr} 2^{-1-}$ and $\mathrm{Fgfr}{ }^{+1-} ; \mathrm{Fgfr}^{-1-} ; \mathrm{Fgfr} 3^{-1-}$, respectively) is sufficient for grossly normal telencephalon and MGE development (Gutin et al., 2006; Paek et al., 2009; Fig. 8A), we tested directly the contribution of FRS proteins in transducing signal from FGFR1 by replacing the single wild-type $F g f r l$ allele in these mice with an Fgfrl allele that is deleted for the FRS-binding-site codons ( $F g f r 1^{\Delta \mathrm{FRS}}$; Hoch and Soriano, 2006). Fgfr ${ }^{\Delta \mathrm{FRS} / \Delta \mathrm{FRS}}$ mutants exhibit a specific deficit in FRS signaling with normal activation of FRS-independent signaling pathways downstream of FGFR1 (Xu et al., 1998; Hoch and Soriano, 2006). We found that the $F g f r 1^{\Delta \mathrm{FRS} /{ }^{-}} ; \mathrm{Fgfr} 2^{-1-}$ phenotype (with a loss of both LGE and MGE) and the Fgfr ${ }^{\Delta \mathrm{FRS} /-} ; \mathrm{Fgfr}^{-1-} ; \mathrm{Fg} f \mathrm{r} 3^{-1-}$ phenotype (with early E8.75 telencephalic precursor cell death) were as severe as the $\mathrm{FgfrI}^{-1-} ; \mathrm{Fgfr} 2^{-1-}$ and $\mathrm{Fgfr}^{-1-} ; \mathrm{Fgfr2}{ }^{-1-} ; \mathrm{Fgfr}^{-1-}$ phenotypes, respectively (Figs. $7 A-C, 8 A, B$ ), indicating that FRS proteins are required to mediate most or all of FGFR1 activity in the early telencephalon. Consistent with this finding, we did not detect telencephalic deficits in mutants in which the wild-type Fgfrl allele was replaced with an allele that lacks the binding site for another classically defined FGFR signaling mediator, PLC $\gamma$ ( $F g f r 1^{\mathrm{Y} 766 \mathrm{~F}}$, Partanen et al., 1998), in an Fgfr2;Fgfr3 mutant background, $\mathrm{Fgfr}^{\mathrm{Y766 \textrm {F } /}}{ }^{-} ; \mathrm{Fgfr}{ }^{-1-} ; \mathrm{Fgfr} 3^{-1-}$ (Fig. $8 \mathrm{~A}$ and data not shown).

\section{Discussion}

With this work, we show a context-dependent requirement for the FRS2 and FRS3 adapters in the developing telencephalon. First, FRS2 and FRS3 are together required for neuronal differentiation of NKX2.1 ${ }^{+}$precursors, but not for early precursor cell 
survival (Figs. 2, 3, 4). Second, FRS adapters are required for differentiation of a subset of neurons in the NKX2.1 ${ }^{+}$domain (Figs. 3, 6). Third, within the differentiating cells, FRS is required for activation of the AKT pathway (Fig. 4). In contrast, FGFR1 signaling via FRS adapters is not required for AKT activation in the context of gross whole embryo development (Hoch and Soriano, 2006; Brewer et al., 2015). Finally, we find that in the telencephalon FRS adapters are required for mediating most or all of FGFR1's activity (Figs. $7 A-C, 8 A, B$ ). The finding that FRS adapters are required to mediate FGFR1 signaling not only in MGE differentiation (Fig. 7), where FRS proteins are themselves required (Fig. 3), but also in early precursor cell survival (Fig. $8 A, B$ ), where, in contrast, FRS proteins are dispensable (Fig. $2 E$ ), suggests that mediators other than FRS proteins participate in transmitting FGFR2 and FGFR3 signaling in early precursors (Fig. $8 C$ ). Moreover, the less severe phenotype of Frs2;Frs3 double mutants compared with Fgfr1; Fgfr2 mutants (e.g., c.f. DLX2, NKX2.1, and LHX8 staining of Frs2; Frs3 mutants in Fig. 3 with staining of Fgfr1;Fgfr 2 mutants in Fig. $7 B$ and in Gutin et al., 2006) also suggests that, at least for FGFR2, adapters other than FRS proteins mediate some signaling in ventral patterning (Fig. 8C).

The finding that FRS adapters are required for mediating most or all of FGFR1's activity in the telencephalon was unexpected. First, FGFR1 has the ability to activate multiple mediators such as Crk/Crkl, PLC $\gamma$, and Grb14 in other contexts (Williams et al., 1994b; Partanen et al., 1998; Turner and Grose, 2010; Goetz and Mohammadi, 2013). Second, a previous study showed that, unlike in the telencephalon, in whole embryos, loss of the FRS2binding site in FGFR1 does not recapitulate the severity of the complete loss of Fgfrl function and that Fgfrl mutants lacking the combined binding sites for FRS2, Crkl, PLC $\gamma$, and Grb14 exhibit a phenotype more severe than loss of the FRS2-binding site alone, indicating that FGFR1 uses transducers other than FRS in other tissues (Brewer et al., 2015).

Our findings are consistent with FRS2 playing a dominant role over FRS3 as a mediator of FGF signaling (Figs. 2D, 3). The phenotype of Frs2-cKO mice observed here is reminiscent of the eye and other CNS deficits of Frs $2^{2 \mathrm{~F} / 2 \mathrm{~F}}$ mutant mice in which the residues encoding the binding sites for Shp2 are mutated (Yamamoto et al., 2005), consistent with FRS2 playing a dominant role over FRS3 in these tissues as well, given the lack of phenotype in Frs3 mutants (Fig. 2D). Likewise, whereas germline deletion of Frs2 is embryonically lethal (Hadari et al., 2001; Gotoh et al., 2005), Frs3 germline knock-out mice develop normally into adulthood (Fig. 2 and data not shown). Despite similarities in the structures of FRS2 and FRS3 and their mechanism of activation, in vitro experiments had implicated FRS2 as the primary mediator of FGF signaling (Gotoh et al., 2005; Gotoh, 2008). Our results confirm a dominant role for FRS2, but also indicate a compensatory role for FRS2 and FRS3 in telencephalon development (Figs. 2, 3).

FRS adapters, in addition to transmitting FGFR signaling, can also transmit signaling from the Ntrk1-, Ntrk2-, and Ntrk3encoded neurotrophin receptors (Ong et al., 2000), making it theoretically possible that part of the Frs 2 and Frs 3 mutant phenotypes observed here are the result of reduced neurotrophin signaling. However, the neurotrophin receptors are either not significantly or not detectably expressed until after neurogenesis has begun between E11.5 and E13.5 and their loss-of-function phenotypes, even when combined, do not include early patterning defects such as those observed here (Minichiello et al., 1995; Minichiello and Klein, 1996). Therefore, it is unlikely that the Frs2 and Frs3 phenotypes described here are the result of reduced signaling though neurotrophin receptors. Moreover, the pheno- types described using the Fgfr $1^{\Delta \text { FRS }}$ allele confirm a role for FRS in mediating FGFR1 signaling in the early telencephalon.

In sum, our observations provide an example of how one intracellular transducer can mediate receptor function within given contexts and, in more general terms, provide a partial explanation for how FGF signaling can promote diverse cellular responses in development and disease.

\section{References}

Basson MA, Echevarria D, Ahn CP, Sudarov A, Joyner AL, Mason IJ, Martinez S, Martin GR (2008) Specific regions within the embryonic midbrain and cerebellum require different levels of FGF signaling during development. Development 135:889-898. CrossRef Medline

Brewer JR, Molotkov A, Mazot P, Hoch RV, Soriano P (2015) Fgfrl regulates development through the combinatorial use of signaling proteins. Genes Dev 29:1863-1874. CrossRef Medline

Corbin JG, Gaiano N, Machold RP, Langston A, Fishell G (2000) The Gsh2 homeodomain gene controls multiple aspects of telencephalic development. Development 127:5007-5020. Medline

Dode C et al. (2003) Loss-of-function mutations in FGFR1 cause autosomal dominant Kallmann syndrome. Nat Genet 33:463-465. CrossRef Medline

Eswarakumar VP, Ozcan F, Lew ED, Bae JH, Tomé F, Booth CJ, Adams DJ, Lax I, Schlessinger J (2006) Attenuation of signaling pathways stimulated by pathologically activated FGF-receptor 2 mutants prevents craniosynostosis. Proc Natl Acad Sci U S A 103:18603-18608. CrossRef Medline

Frantz GD, Bohner AP, Akers RM, McConnell SK (1994) Regulation of the POU domain gene SCIP during cerebral cortical development. J Neurosci 14:472-485. Medline

Goetz R, Mohammadi M (2013) Exploring mechanisms of FGF signalling through the lens of structural biology. Nat Rev Mol Cell Biol 14:166-180. CrossRef Medline

Gotoh N (2008) Regulation of growth factor signaling by FRS2 family docking/scaffold adaptor proteins. Cancer Sci 99:1319-1325. CrossRef Medline

Gotoh N, Laks S, Nakashima M, Lax I, Schlessinger J (2004) FRS2 family docking proteins with overlapping roles in activation of MAP kinase have distinct spatial-temporal patterns of expression of their transcripts. FEBS Lett 564:14-18. CrossRef Medline

Gotoh N, Manova K, Tanaka S, Murohashi M, Hadari Y, Lee A, Hamada Y, Hiroe T, Ito M, Kurihara T, Nakazato H, Shibuya M, Lax I, Lacy E, Schlessinger J (2005) The docking protein FRS2alpha is an essential component of multiple fibroblast growth factor responses during early mouse development. Mol Cell Biol 25:4105-4116. CrossRef Medline

Guillemot F, Zimmer C (2011) From cradle to grave: the multiple roles of fibroblast growth factors in neural development. Neuron 71:574-588. CrossRef Medline

Gutin G, Fernandes M, Palazzolo L, Paek H, Yu K, Ornitz DM, McConnell SK, Hébert JM (2006) FGF signalling generates ventral telencephalic cells independently of SHH. Development 133:2937-2946. CrossRef Medline

Hadari YR, Gotoh N, Kouhara H, Lax I, Schlessinger J (2001) Critical role for the docking-protein FRS2 alpha in FGF receptor-mediated signal transduction pathways. Proc Natl Acad Sci U S A 98:8578-8583. CrossRef Medline

Hébert JM (2011) FGFs: neurodevelopment's jack-of-all-trades-how do they do it? Front Neurosci 5:133. CrossRef Medline

Hébert JM, Fishell G (2008) The genetics of early telencephalon patterning: some assembly required. Nat Rev Neurosci 9:678-685. CrossRef Medline

Hébert JM, McConnell SK (2000) Targeting of cre to the Foxg1 (BF-1) locus mediates loxP recombination in the telencephalon and other developing head structures. Dev Biol 222:296-306. CrossRef Medline

Hébert JM, Lin M, Partanen J, Rossant J, McConnell SK (2003) FGF signaling through FGFR1 is required for olfactory bulb morphogenesis. Development 130:1101-1111. CrossRef Medline

Hoch RV, Soriano P (2006) Context-specific requirements for Fgfr 1 signaling through Frs2 and Frs3 during mouse development. Development 133:663-673. CrossRef Medline

Hoch RV, Clarke JA, Rubenstein JL (2015) Fgf signaling controls the telencephalic distribution of Fgf-expressing progenitors generated in the rostral patterning center. Neural Dev 10:8. CrossRef Medline

Hryciw T, MacDonald JIS, Phillips R, Seah C, Pasternak S, Meakin SO (2010) 
The fibroblast growth factor receptor substrate 3 adapter is a developmentally regulated microtubule-associated protein expressed in migrating and differentiated neurons. J Neurochem 112:924-939. CrossRef Medline

Huang L, Watanabe M, Chikamori M, Kido Y, Yamamoto T, Shibuya M, Gotoh N, Tsuchida N (2006) Unique role of SNT-2/FRS2b/FRS3 docking/adaptor protein for negative regulation in EGF receptor tyrosine kinase signaling pathways. Oncogene 25:6457-6466. CrossRef

Johnson DE, Lu J, Chen H, Werner S, Williams LT (1991) The human fibroblast growth factor receptor genes: a common structural arrangement underlies the mechanisms for generating receptor forms that differ in their third immunoglobulin domain. Mol Cell Biol 11:4627-4634. CrossRef Medline

Kang W, Balordi F, Su N, Chen L, Fishell G, Hébert JM (2014) Astrocyte activation is suppressed in both normal and injured brain by FGF signaling. Proc Natl Acad Sci U S A 111:E2987-E2995. CrossRef Medline

Kohwi M, Osumi N, Rubenstein JL, Alvarez-Buylla A (2005) Pax6 is required for making specific subpopulations of granule and periglomerular neurons in the olfactory bulb. J Neurosci 25:6997-7003. CrossRef Medline

Lin Y, Zhang J, Zhang Y, Wang F (2007) Generation of an Frs2alpha conditional null allele. Genesis 45:554-559. CrossRef Medline

Liodis P, Denaxa M, Grigoriou M, Akufo-Addo C, Yanagawa Y, Pachnis V (2007) Lhx6 activity is required for the normal migration and specification of cortical interneuron subtypes. J Neurosci 27:3078-3089. CrossRef Medline

Mason I (2007) Initiation to end point: the multiple roles of fibroblast growth factors in neural development. Nat Rev Neurosci 8:583-596. CrossRef Medline

Miki T, Bottaro DP, Fleming TP, Smith CL, Burgess WH, Chan AM, Aaronson SA (1992) Determination of ligand-binding specificity by alternative splicing: two distinct growth factor receptors encoded by a single gene. Proc Natl Acad Sci U S A 89:246-250. CrossRef Medline

Minegishi Y, Iwanari H, Mochizuki Y, Horii T, Hoshino T, Kodama T, Hamakubo T, Gotoh N (2009) Prominent expression of FRS2b protein in neural cells and its association with intracellular vesicles. FEBS Lett 583: 807-814. CrossRef

Minichiello L, Klein R (1996) TrkB and TrkC neurotrophin receptors cooperate in promoting survival of hippocampal and cerebellar granule neurons. Genes Dev 10:2849-2858. CrossRef Medline

Minichiello L, Piehl F, Vazquez E, Schimmang T, Hökfelt T, Represa J, Klein R (1995) Differential effects of combined trk receptor mutations on dorsal root ganglion and inner ear sensory neurons. Development 121: 4067-4075. Medline

Muenke M, Schell U, Hehr A, Robin NH, Losken HW, Schinzel A, Pulleyn LJ, Rutland P, Reardon W, Malcolm S (1994) A common mutation in the fibroblast growth factor receptor 1 gene in Pfeiffer syndrome. Nat Genet 8:269-274. CrossRef Medline

Ong SH, Guy GR, Hadari YR, Laks S, Gotoh N, Schlessinger J, Lax I (2000) FRS2 proteins recruit intracellular signaling pathways by binding to di- verse targets on fibroblast growth factor and nerve growth factor receptors. Mol Cell Biol 20:979-989. CrossRef Medline

Paek H, Gutin G, Hébert JM (2009) FGF signaling is strictly required to maintain early telencephalic precursor cell survival. Development 136: 2457-2465. CrossRef Medline

Paek H, Hwang JY, Zukin RS, Hébert JM (2011) beta-Catenin-dependent FGF signaling sustains cell survival in the anterior embryonic head by countering Smad4. Dev Cell 20:689-699. CrossRef Medline

Partanen J, Schwartz L, Rossant J (1998) Opposite phenotypes of hypomorphic and Y766 phosphorylation site mutations reveal a function for Fgfr 1 in anteroposterior patterning of mouse embryos. Genes Dev 12:23322344. CrossRef Medline

Storm EE, Garel S, Borello U, Hebert JM, Martinez S, McConnell SK, Martin GR, Rubenstein JL (2006) Dose-dependent functions of Fgf8 in regulating telencephalic patterning centers. Development 133:1831-1844. CrossRef Medline

Tole S, Gutin G, Bhatnagar L, Remedios R, Hébert JM (2006) Development of midline cell types and commissural axon tracts requires Fgfrl in the cerebrum. Dev Biol 289:141-151. CrossRef Medline

Turner N, Grose R (2010) Fibroblast growth factor signalling: from development to cancer. Nat Rev Cancer 10:116-129. CrossRef Medline

Williams EJ, Furness J, Walsh FS, Doherty P (1994a) Activation of the FGF receptor underlies neurite outgrowth stimulated by L1, N-CAM, and N-cadherin. Neuron 13:583-594. CrossRef Medline

Williams EJ, Furness J, Walsh FS, Doherty P (1994b) Characterisation of the second messenger pathway underlying neurite outgrowth stimulated by FGF. Development 120:1685-1693. Medline

Xiao S, Nalabolu SR, Aster JC, Ma J, Abruzzo L, Jaffe ES, Stone R, Weissman SM, Hudson TJ, Fletcher JA (1998) FGFR1 is fused with a novel zincfinger gene, ZNF198, in the $t(8 ; 13)$ leukaemia/lymphoma syndrome. Nat Genet 18:84-87. CrossRef Medline

Xu H, Lee KW, Goldfarb M (1998) Novel recognition motif on fibroblast growth factor receptor mediates direct association and activation of SNT adapter proteins. J Biol Chem 273:17987-17990. CrossRef Medline

Xu Q, Guo L, Moore H, Waclaw RR, Campbell K, Anderson SA (2010) Sonic hedgehog signaling confers ventral telencephalic progenitors with distinct cortical interneuron fates. Neuron 65:328-340. CrossRef Medline

Yamamoto S, Yoshino I, Shimazaki T, Murohashi M, Hevner RF, Lax I, Okano H, Shibuya M, Schlessinger J, Gotoh N (2005) Essential role of Shp2-binding sites on FRS2alpha for corticogenesis and for FGF2dependent proliferation of neural progenitor cells. Proc Natl Acad Sci U S A 102:15983-15988. CrossRef Medline

Zhang Y, McKeehan K, Lin Y, Zhang J, Wang F (2008) Fibroblast growth factor receptor 1 (FGFR1) tyrosine phosphorylation regulates binding of FGFR substrate 2alpha (FRS2alpha) but not FRS2 to the receptor. Mol Endocrinol 22:167-175. CrossRef Medline

Zhao Y, Marín O, Hermesz E, Powell A, Flames N, Palkovits M, Rubenstein JL, Westphal H (2003) The LIM-homeobox gene Lhx8 is required for the development of many cholinergic neurons in the mouse forebrain. Proc Natl Acad Sci U S A 100:9005-9010. CrossRef Medline 